$\mathrm{M}$

еланома кожи: от системной биологии к персонифицированной терапии

\author{
Т.Г. Рукша, М.Б. Аксененко, Е.Ю. Сергеева, Ю.А. Фефелова
}

ГБОУ ВПО «Красноярский государственный медицинский университет имени профессора В.Ф. Войно-Ясенецкого» Миниздрава России

660022, Красноярск, ул. П. Железняка, д. 1

Системная биология является новой областью биомедицины, в основе которой лежит интегративный подход

к рассмотрению молекулярных механизмов функционирования живых систем, в том числе при развитии

патологических процессов. В этой связи современные терапевтические подходы в отношении меланомы кожи

могут быть рассмотрены на основании ключевых изменений межмолекулярных взаимодействий, происходящих

при соормировании данной опухоли.

Ключевые слова: системная биология, меланома кожи, сигнальные пути.

Контактная информация: tatyana_ruksha@mail.ru Вестник дерматологии и венерологии 2013; (1): 4_8.

\title{
Skin melanoma: from systematic biology to the personalized therapy
}

T.G. Ruksha, M.B. Aksenenko, Ye.Yu. Sergeyeva, Yu.A. Fefelova

Krasnoyarsk State Medical University

P. Zheleznyaka street, 1, 660022, Krasnoyarsk, Russia

Systematic biology is a new field of biomedicine based on the integrative approach to molecular mechanisms of the operation of living systems including in case of the development of pathological processes. In this connection, up-to-date therapeutic approaches to skin melanoma treatment can be considered on the basis of key changes in intermolecular interactions taking place during tumor development.

Key words: systematic biology, skin melanoma, signal paths.

Corresponding author: tatyana_ruksha@mail.ru. Vestnik Dermatologii i Venerologii 2013; 1: 4—8. 
Успешная реализация программы «Геном человека», которая завершилась в 2003 г., а также растущая доступность анализа нуклеиновых кислот, белков, различных метаболитов в значительной степени изменяют представление о патогенезе заболеваний в последнее десятилетие. Многочисленные исследования в области биомедицины способствовали формированию новых концепций о механизмах развития болезней как о комплексных нарушениях межмолекулярных взаимодействий [1]. На основе этого сфрормировалась и развивается новая наука - системная биология, являющаяся областью академической науки, в основе которой лежит интеграция биологических данных с целью объективного анализа функционирования сложных систем, к которым относится в том числе и человек. Посредством изучения больших массивов экспериментальных данных с помощью методов биоинформатики системная биология ставит перед собой следующие задачи: анализ сетей взаимодействий генов, биохимических путей, их динамических изменений, целенаправленная модуляция их функционирования, а также их воссоздание [2]. Прикладными задачами системной биологии в отношении медицины являются изменение медицины в сторону персонализированного и предиктивного подхода на основе молекулярно-генетического скрининга каждого индивида. Ли Худ - один из руководителей проекта «Геном человека», директор Института системной биологии в Сиэтле - сформулировал основные направления, по которым, по всей вероятности, будет развиваться медицина в XXI веке. Эти направления легли в основу его так называемой концепции «П-4» - прогнозный, персонализированный, профилактический и пациентоориентированный подходы [3].

Таким образом, патогенез заболевания с современных позиций может рассматриваться как специфический тип нарушений функционирования систем, отражающих взаимодействие белковых молекул, ДНК, РНК и различных метаболитов [4]. В связи с этим важно понимать не только составляющие механизмов, лежащих в основе развития заболевания, но также представлять те динамические изменения межмолекулярных взаимодействий, составляющих основу развития заболевания, с позиций системной биологии [5].

Современные технологии позволяют осуществлять прогнозирование развития определенного заболевания. В частности, анализ генетического профиля пациента может указать врачу возможные предикторы развития заболевания, более того, прогнозировать эффективность терапии [6]. Вариации нуклеотидной последовательности ДНК используются в качестве молекулярно-генетических маркеров и могут быть применены для выявления предрасположенности к ряду заболеваний. В частности, если речь идет о дерматологических заболеваниях, то в качестве примера можно привести витилиго - хроническое заболевание кожи, в основе которого лежит деградация меланоцитов - клеток эпидермиса, продуцирующих пигмент меланин. Показано, что носители мутантного аллеля гена каталазы подвержены более высокому риску развития витилиго, потому что у данной группы людей снижаются уровень и активность фрермента каталазы, метаболизирующей перекись водорода. В условиях повышенной концентрации перекиси водорода, возникающей при этом в меланоцитах, ее повреждающее действие приводит к гибели меланоцитов и, как следствие, снижается уровень пигмента в коже, что проявляется возникновением депигментированных пятен у больных [7].

Началом фрормирования стратегий персонифицированной терапии следует считать создание препарата герцептин, эффрективного при лечении рака молочной железы только у пациенток с повышенным уровнем белка HER-2, относящегося к семейству рецепторов эпидермального фрактора роста. Повышение уровня экспрессии HER-2B вызывает изменение процессов пролиферации, диффреренцировки и связано с развитием рака легкого, молочной железы, яичников [8].

Другим примером подобного подхода является использование иматиниба в лечении больных хроническим миелолейкозом, у которых обнаруживается химерный ген bcr-abl [9]. Персонификация терапии стала возможной после разработки технологий молекулярно-генетического скрининга и создания методологических основ его применения в практической медицине. На основе генотипирования каждого пациента становится возможным не только предусмотреть ответ организма на терапию, развитие осложнений, но и выбрать максимально эффрективную дозу лекарственного препарата для каждого пациента. Возможность генотипирования определяет также новые перспективы развития профилактического аспекта современной медицины. В частности, если у пациента есть риск возникновения рака молочной железы 40\% в возрасте 50 лет, то при проведении ранней профилактики с 35-летнего возраста риск развития данного заболевания снижается к 50 годам до 5\%. Пациентоориентированный (партиципативный) подход подразумевает активное участие пациента и его персональный выбор своей судьбы [3].

Необходимо отметить, что в результате расшифрровки генома стало понятным, что геном отдельно взятого индивида отличается от генома другого индивида менее чем на 1\% [10]. При этом именно эта незначительная разница обеспечивает физические отличия каждого человека от другого, а также фрормирует различия в предрасположенности отдельного человека к тому или иному заболеванию.

Несомненную значимость имеют достижения клеточной и молекулярной биологии для понимания механизмов развития злокачественных новообразований. 
К ключевым молекулярным событиям при канцерогенезе с позиций современных знаний можно отнести нелетальные изменения генетического аппарата клетки, происходящие преимущественно под действием канцерогенов, прежде всего в генах, подавляющих опухолевый рост, модулирующих апоптоз и ответственных за репарацию ДНК. Вследствие указанных изменений генетического аппарата формируются моноклональные опухолевые клетки. Таким образом, канцерогенез является многоступенчатым процессом, характеризующимся первоначальными изменениями на уровне генома, что является следствием многочисленных мутаций $[11,12]$. Это обусловливает гетерогенность злокачественных новообразований даже в пределах одной нозологической формы. При этом становится очевидным, что не менее важным при формировании злокачественных новообразований является наличие дисрегуляции многочисленных механизмов передачи сигнала, участвующих в обеспечении нормального хода процессов пролиферации, дифференцировки, апоптоза и миграции клеток [13].

\section{Молекулярные основы канцерогенеза при меланоме}

По сравнению с другими органами кожа подвергается действию канцерогенов в первую очередь, что объясняет высокую частоту малигнизации ее тканей: в структуре заболеваемости злокачественными новообразованиями в Российской Федерации опухоли кожи занимают второе место [14]. Данный фракт может быть обусловлен частым прямым контактом с патогенными факторами внешней среды [15, 16]. Меланома кожи относится к наиболее агрессивно протекающим злокачественным новообразованиям [17]. Заболеваемость меланомой кожи увеличивается практически повсеместно во всем мире, при этом отсутствует эффективная терапия метастазирующих меланом. Медиана выживаемости при метастазирующей меланоме кожи составляет 8-9 мес., а трехлетняя выживаемость - менее 15\% [18].

Возможность секвенирования генома человека позволила в значительной степени изменить понимание молекулярного патогенеза данного новообразования. Многочисленные молекулярные события, сопровождающие развитие и прогрессию данного заболевания, позволяют рассматривать меланому кожи так же, как проявление комплексного нарушения механизмов передачи сигнала [19].

Пролиферация, дифференцировка и миграция являются ключевыми событиями в нормальной физиологии меланоцитов [20]. Функционирование сигнальных механизмов, регулирующих эти процессы, изменяется в клетках меланомы [21]. В связи с этим складывается впечатление, что при меланоме нарушается функционирование сигнальных путей, а не только отдельно взятых генов и их продуктов. Сравнительно недавно были идентифицированы сигнальные механизмы, нарушения которых регистрируются наиболее часто при развитии меланомы кожи [22]. В дальнейшем было выявлено, что не все меланомы кожи развиваются по одним и тем же механизмам.

В частности, обнаружено, что в случае развития меланомы кожи на участках тела, не подверженных хроническому воздействию ультрафиолетового излучения, определяются мутации генов BRAF и NRAS, В то время для меланом, расположенных на участках кожи, подверженных частому воздействию ультрафиолетового излучения, мутации гена BRAF не характерны [20].

RAS относится к семейству сигнальных G-белков, регулирующих рост и деление клеток, и является компонентом двух сигнальных путей - митогенактивируемых протеинкиназ (МАРК) и фосфратидилинозитолтрикиназного (РІЗК) пути [23]. Обнаружено, что до 90\% меланом, а также доброкачественных меланоцитарных новообразований кожи (меланоцитарных невусов) имеют активирующие мутации генов сигнального каскада MAPK - NRAS или BRAF, что является несомненным доказательством роли последних в развитии данных новообразований [24, 25]. Таким образом, с одной стороны, активация МАРК, несомненно, играет важную роль в развитии нарушений пролиферации меланоцитов, но при этом не является единственным событием на пути опухолевой трансформации меланоцитов. Помимо этого изменения PI3K встречаются в 50-60\% меланом. Мутации RAS приводят к активации механизмов передачи сигнала МАРК и РІЗК и, как следствие, пролиферации меланоцитов. При этом считается, что мутации одного только этого гена недостаточно для индукции непосредственного развития злокачественного новообразования [26].

Мутации гена BRAF встречаются менее чем в 20\% случаев рака различных локализаций, но в 80-90\% случаев при меланоме кожи. Как и мутация NRAS, данная мутация определяется также в доброкачественных меланоцитарных новообразованиях, указывая, что наличия только мутации данного гена недостаточно для опухолевой трансформации [27]. NRAS играет роль в активации не только сигнального механизма MAPK, но и PIЗK: активация RAS вызывает мембранную транслокацию и активацию РІЗК. Фосфрорилирование фосфратидилинозитол-3,4,5-трифосфрата приводит в свою очередь к активации наиболее важного эффекторного белка данного сигнального каскада - Akt [28]. Важно отметить, что мутация гена BRAF является приобретенной и регистрируется непосредственно в опухолевых клетках. Важным также является и то, что до сих пор непосредственный механизм развития данной мутации неизвестен. Одна из гипотез заключается в том, что, возможно, индуцированное воздействием ультрафиолетового излучения образо- 
вание пиримидиновых димеров в соседней позиции вызывает появление собственно мутации гена BRAF в позиции 600 [29].

\section{Диагностика мутаций в меланоцитарных опухолях как основа создания способов персонифицированной терапии}

Высокая частота мутаций гена BRAF, наблюдающаяся при меланоме кожи, позволила предположить, что BRAF является идеальной молекулярной мишенью для терапии данного заболевания. Первым неселективным ингибитором BRAF был сорафениб, который также модулирует активность фрактора роста сосудистого эндотелия и рецептора тромбоцитарного фактора роста [30]. Первые клинические испытания сорафениба в качестве монотерапии при метастазирующей меланоме кожи не выявили значимого эффекта. В дальнейшем проводились попытки сочетанной терапии сорафенибом с препаратами платины, дакарбазином, эфрфективность которой была более высокой [31]. Одним из первых селективных BRAF ингибиторов является PLX4032/RG7204 [32]. При проведении первой фразы клинических испытаний было показано, что у $81 \%$ BRAF-позитивных больных меланомой кожи наблюдалась регрессия опухоли [33]. К сожалению, как оказалось позднее, клинический эффрект был нестойким. К механизмам, лежащим в основе развития противоопухолевой резистентности, относят реактивацию сигнального каскада RAF - MEK, активацию других механизмов передачи сигналов, также приводящих к нерегулируемому увеличению пролиферации меланоцитов, эпигенетические изменения, в частности ремоделирование хроматина [34]. Именно такая высокая пластичность клеток меланомы кожи позволяет ей оставаться одной из наиболее резистентных к химиотерапии опухолей.

Предполагается, что меланома, возникающая в области слизистых оболочек, ладоней и ногтевых пластин (так называемая акральная меланома), имеет иной молекулярный патогенез. Так, при данных клинических формах меланомы отсутствует активация MAPK сигнального каскада, не регистрируются мутации гена BRAF. Но при этом было обнаружено, что при данном типе опухоли выявляются мутации гена KIT [35]. Как и в случае с BRAF, мутации данного гена не являются специфичными только для меланомы кожи и определяются при опухолях желудочно-кишечного тракта, карциноме легкого и остром миелолейкозе. Мутации гена KIT были обнаружены у 39\% больных меланомой слизистых оболочек, 36\% больных с акральной фрормой меланомы кожи и в $28 \%$ случаев меланомы кожи, развившихся в участках кожи, подверженных хроническому воздействию ультрафиолетового излучения [36]. Более того, мутации гена КІT были зарегистрированы в 88\% случаев меланомы, локализованной в полости рта, а также в $10 \%$ случа- ев меланомы в области анального отверстия [37, 38]. В Российской Федерации в проведенном пилотном исследовании мутации гена КIT были обнаружены в 17\% случаев меланомы слизистых оболочек [39]. Результаты клинических испытаний показали эффективность иматиниба при лечении больных меланомой с мутацией гена KIT [40]. В частности, при лечении 43 пациентов иматинибом в дозе 400 мг ежедневно у $42 \%$ из них отмечалось уменьшение размера опухоли, увеличение продолжительности жизни, что подтверждает возможность использования с-Kit в качестве молекулярной мишени. В дальнейшем был разработан киназный ингибитор второго поколения в отношении c-Kit - нилотиниб, также протестированный в случаях c-Kit-позитивных меланом. Иматиниб является ингибитором рецептора тирозинкиназы, который эффрективен в ингибировании BCR-ABL - продукта химерного гена при остром миелолейкозе, но также и в отношении с-Kit [41].

\section{Новые терапевтические подходы к лечению меланомы кожи}

Высокая пластичность клеток меланомы, позволяющая успешно избегать индуцирующих апоптоз стимулов, быстрое развитие резистентности к лекарственным препаратам, в том числе блокирующим адекватные молекулярные мишени, предполагает необходимость применения комбинированной терапии. Так, при одновременном назначении сорафениба и рапамицина наблюдалось более выраженное снижение пролиферации клеток меланомы [42]. Осуществлялись попытки сочетанного блокирования сигнального пути МАРК и воздействия на семейство апоптозмодулирующих белков Bcl-2. Были найдены также положительные противоопухолевые эффекты при таких комбинациях [43]. Таким образом, предполагается, что селективный подход к терапии меланомы кожи на основе выявления подтипов опухоли, различающихся по молекулярным механизмам развития, является перспективным, и необходимы дальнейшие исследования для оптимизации режимов данной терапии и исключения развития резистентности.

Резюмируя особенности патогенеза меланомы кожи, следует отметить, что множественные нарушения механизмов передачи сигнала, наблюдаемые при меланоме кожи и затрагивающие различные аспекты жизнедеятельности клеток (рост, дифференцировку, подвижность, метастазирование, гибель), не позволяют вызвать координированную блокаду всех патологических изменений, происходящих при развитии данной опухоли. Терапия запущенных фрорм меланомы остается малоэффективной, что требует дальнейших исследований на геномном и постгеномном уровнях для целостного понимания механизмов развития данного заболевания. 


\section{Литература}

1. Galas D., Hood L. Systems biology and emerging technologies will catalyze the transition from reactive medicine to predictive, personalized, preventive and participatory (P4) medicine. Interdisciplinary Biocentre 2009; 6: 1 - 4 .

2. Sverdlov E.D. Vzglyad na zhizn' cherez okno genoma M: Nauka 2009. [Свердлов Е.Д. Взгляд на жизнь через окно генома. М: Наука 2009.]

3. Sol A. del, Balling R., Hood L. et al. Disease as network pertubations. Curr Opinion Biotechnol 2010; 21: $556-571$.

4. Stelling J., Sauer U., Szallasi Z. et al. Robustness of celIular functions. Cell 2004; 118: 675-685.

5. Zhu X., Gerstein M., Snyder M. Getting connected: analysis and principles of biological networks. Genes \& Development 2007; 21: 1010-1024.

6. Diamandis M., White N.M.A., Yousef G.M. Personalized medicine: marking a new epoch in cancer patient management. Molec Cancer Res 2010; 8: 11751187.

7. Schallreuter K.U., Salem M.A., Gibons N.C. et al. Blunted epidermal L-tryptophan metabolism in vitiligo affects immune response and ROS scavenging by Fenton chemistry, part 1: epidermal H202/0NOO-mediated stress abrogates tryptophan hydroxylase and dopa decarboxylase activities, leading to low serotonin and melatonin levels. FASEB J 2012; 26: $247-2470$

8. Guan H., Jia S.-F., Zhou Z. et al. Herceptin downregulates HER-2/neu and vascular endothelial growth factor expression and enhances taxol-induced cytotoxicity of human Ewing's sarcoma cells in vitro and in vivo. Clin Cancer Res 2005; 11: 2008_2017.

9. Nikolaou V.A., Stratigos A.J., Flaherty K.T. et al. Melanoma: new insight and new therapies. $J$ invest Derm 2012; 132: 854-863.

10. Kumar V. Pathologic basis of disease. Philadelphia: Saunders Elsevier; 2010.

11. Wu R.Q., Zhao X.F., Wang Z.Y. Novel molecular events in oral carcinogenesis via integrative approaches. J Dental Res 2011; 90: 561—572.

12. Huang S., Ernberg I., Kauffman S. Cancer attractors: a systems view of tumors from a gene network dynamics and developmental perspective. Seminars in Cell and Developmental Biology 2009; 20: 869_876.

13. Kreeger P.K., Lauffenburger D.A. Cancer systems bioogy: a network modeling perspective. Carcinogenesis 2010; 31:2-8.

14. Zlokachestvennye novoobrazovaniya v Rossii v 2010 godu (zabolevaemost' i smertnost'). Pod redakciej Chissova V.I., Starinskogo V.V., Petrovoj G.V. M: FGBU «MNIOI im. P.A. Gercena» Minzdravsocrazvitiya Rossii 2012. [Злокачественные новообразования в России в 2010 г. (заболеваемость и смертность). Под редакцией В.И. Чиссова. В.В. Старинского, Г.В. Петровой. М: ФГБУ «МНИОИ им. П.А. Герцена» Минздравсоцразвития России 2012.]
15. Bulliard J.L., Panizzon R.G., Levi F. Epidemiology of epithelial skin cancers. Rev méd suisse 2009; 5 : 884-888.

16. Kim R.H., Armstrong A.W. Nonmelanoma skin cancer. Dermatologic Clinics 2012; 30: 125-139

17. Lemech C., Infante J., Arkenau H.T. The potential for BRAF V600 inhibitors in advanced cutaneous melanoma: rationale and latest evidence. Ther Adv Med Oncol 2012; 4: 61-73.

18. Balch C.M., Gershenwald J.E., Soong S.J. et al. Final version of 2009 AJCC melanoma staging and classification. J Clin Oncol 2009; 27: 6199—6206.

19. Ko J.M., Velez N.F., Tsao H. Pathways to melanoma. Seminar in Cutaneous Medicine and Surgery 2010; 29: 210-217.

20. Khaled M., Levy C., Fisher D.E. Control of melanocyte differentiation by a MITF-PDE4D3 homeostatic circuit. Genes \& Development 2010; 24: 2276-2281.

21. Smalley K.S.M., Haass N.K., Brafford P.A. et al. Multiple signaling pathways must be targeted to overcome drug resistance in cell lines derived from melanoma metastases. Mol Cancer Ther 2006; 5: 1136-1144.

22. Yazdi A.S., Ghoreschi K., Sander C.A. et al. Activation of the mitogen-activated protein kinase pathway in malignant melanoma can occur independently of the BRAF T1799A mutation. Eur J Dermatol 2010; 20: 575-579.

23. Gelb B.D., Tartaglia M. Noonan syndrome and related disorders: dysregulated RAS-mitogen activated protein kinase signal transduction. Hum Molec Genet 2006; 15: R220-R226.

24. Gyrylova S.N., Ruksha T.G. Zobova S.N. et al. Assessment of the BRAF status in patients with skin melanoma. Vestn Dermatol Venerol 2011; 6: 27-30. [Гырылова С.Н., Рукша Т.Г., Комина А.В. и др. Анализ BRAF-статуса при меланоме кожи. Вестн дерматол венерол 2011; 6: 27-30.]

25. Smalley K.S.M., Nathanson K.L., Flaherty K.T. Genetic subgrouping of melanoma reveals new opportunities for targeted therapy. Cancer Res 2009; 69: 32413244.

26. Hocker T.L., Songh M.K., Tsao H. Melanoma genetics and therapeutic approaches in the 21st century: moving from the benchside to the bedside. $J$ invest Derm 2008; 128: 2575-2595.

27. Taube J.M., Begum S., Shi C. et al. Benign nodal nevi frequently harbor the activating V600E BRAF mutation. Am J Surg Pathol 2009; 33: 568-571.

28. Davies M.A., Stemke-Hale K., Lin E. et al. Integrated molecular and clinical analysis of AKT activation in metastatic melanoma. Clin Cancer Res 2009; 15: 7538-7546.

29. Curtin J.A., Fridland J., Kageshita T. Distinct sets of genetic alterations in melanoma. J invest Derm 2005; 126: $1660-1663$
30. Wilhelm S.M., Adnane L., Newell P. et al. Preclinical overview of sorafenib, a multikinase inhibitor that targets both Raf and VEGF and PDGF receptor tyrosine kinase signaling. Mol Cancer Therap 2008; 7: 3129_ 3140.

31. Jilaveanu L., Zito C., Lee S.J. et al. Expression of sorafenib targets in melanoma patients treated with carboplatin, paclitaxel and sorafenib. Clin. Cancer Res 2009; 15: 1076-1085

32. Bollag G., Hirth P., Tsai J. et al. Clinical efficacy of a RAF inhibitor needs broad target blockade in BRAFmutant melanoma. Nature 2010; 467: 596 — 599.

33. Flaherty K.T. Narrative review: BRAF opens the door for therapeutic advances in melanoma. Ann Int Medicine 2010; 153: 587-591.

34. Aplin A.E., Kaplan F.M., Shao Y. Mechanisms of resistance to RAF inhibitors in melanoma. J invest Derm 2011; 131: 1817-1820.

35. Carvajal R.D., Antonescu C.R., Wolchok Jedd D. et al. KIT as a therapeutic target in metastatic melanoma. JAMA 2011; 305: 2327-2334.

36. Curtin J.A., Busam K., Pinkel D. et al. Somatic activation of KIT in distinct subtypes of melanoma. J Clin Oncol 2006; 24: 4340 — 4346.

37. Rivera R.S., Nagatsuka H., Gunduz M. et a. C-kit protein expression correlated with activating mutations in KIT gene in oral mucosal melanoma. Virchows Archiv 2008; 452(1): 27-32.

38. Antonescu C.R., Busam K.J., Francone T.D. L576P KIT mutation in anal melanomas correlates with KIT protein expression and is sensitive to specific kinase inhibition. Int J Cancer 2007: 121: 257-264.

39. Abysheva S.N., Iyevleva A.G., Efimova N.V. et al. KIT mutations in Russian patients with mucosal melanoma. Melanoma Research 2011; 21: 555-559.

40. Chevallier P., Hunault-Berger M., Larosa F. et al. A phase II trial of high-dose imatinib mesylate for relapsed or refractory c-kit positive and Bcr-Abl negative acute myeloid leukaemia: the AFR-15 trial. Leukocyte Research 2009; 33: 1124-1126.

41. Guo J., Si L., Kong Y. et al. Phase II, open-label, single-arm trial of imatinib mesylate in patients with metastatic melanoma harboring c-Kit mutation or amplification. J Clin Oncol 2011: 29: 2904-2909.

42. Molhoek K.R., Brautigan D.L., Slingluff C.L. et al. Synergistic inhibition of human melanoma proliferation by combination treatment with B-Raf inhibitor BAY43-9006 and mTOR inhibitor Rapamycin. J Translational Medicine 2005; $3: 39$.

43. Wang Y.F. Jiang C.C., Kiejda K.A. et al. Apoptosis induction in human melanoma cells by inhibition of MEK is caspase-independent and mediated by the $\mathrm{BCl}-2$ family members PUMA, Bim, and Mcl-1. Clin Cancer Res 2007; 13: 4934— 4942.

об авторах:

Т.Г. Рукша - д.м.Н., зав. кафедрой патофизиологии с курсом клинической патофизиологии

М.Б. Аксененко - к.м.н., ассистент кафедры патофизиологии с курсом клинической патофизиологии

Е.Ю. Сергеева — профессор, кафедры патосизиологии с курсом клинической патосризиологии

Ю.А. Фефелова - доцент, кафедры патофизиологии с курсом клинической патофизиологии 